\title{
When character forges the crisis: Personality traits of world leaders and differential policy responses to the COVID-19 pandemic
}

\section{Mike Medeiros}

Department of Political Science, University of Amsterdam https://orcid.org/0000-0001-7359-272X Alessandro Nai ( $\sim$ a.nai@uva.nl)

Amsterdam School of Communication Research, University of Amsterdam https://orcid.org/00000001-7303-2693

\section{Ayşegül Erman}

Toronto General Hospital Research Institute, University Health Network, University of Toronto https://orcid.org/0000-0003-0441-3497

\section{Elizabeth Young}

Department of Sociology, Tilburg University

\section{Research Article}

Keywords: COVID-19, political elites, personality, policy, comparative analysis

Posted Date: February 16th, 2021

DOI: https://doi.org/10.21203/rs.3.rs-211261/v2

License: (c) (1) This work is licensed under a Creative Commons Attribution 4.0 International License. Read Full License 


\section{Abstract}

The rapidly growing scholarship on the COVID-19 crisis has focused on a variety of macro-level factors to understand government policy responses. The current study addresses an important gap in this line of research by evaluating the extent to which government leaders' personality traits have led to divergent policy responses during the pandemic. To do so, we use data from the Oxford COVID-19 Government Response Tracker initiative (OxCGRT) to measure differences in both the speed and magnitude of these responses across countries and NEGex, a dataset that maps the personality traits of current heads of government (presidents or prime ministers) in 61 countries. Our results show that personality matters. We find that world leaders scoring high on "plasticity" (extraversion, openness) provide a stronger overall response, as well as a more rapid response in terms of financial relief. Whereas, leaders scoring high on "stability" (conscientiousness, agreeableness, emotional stability) offer both a quicker and stronger financial relief response. Our findings underscore the need to account for the personality of decisionmakers when exploring policy decisions taken during the COVID-19 pandemic, as well as during other crisis situations.

\section{Introduction}

"The chancellor's [Angela Merkel] rigor in collating information, her honesty in stating what is not yet known, and her composure are paying off" (Miller 2020).

"This is a man-made disaster, and that man is Donald Trump" (Tomasky 2020).

The COVID-19 pandemic has forced government around the world to swiftly and simultaneously respond to a new and emerging crisis. Yet, countries have had markedly different responses to the COVID-19 pandemic, ranging from near-total lockdowns (e.g. New Zealand) to few formal restrictions (e.g. Sweden) to promoting mass public gatherings (e.g. Nicaragua). The two characterizations above of the COVID-19 crisis highlight the influence that leaders are perceived to have had on outcomes, both in terms of policy responses and health consequences (cases and deaths). While the differing responses have typically been attributed to a variety of macro-level factors, for instance, economic, cultural, and political factors, as well as, demographic risk factors and limitations in medical infrastructure (e.g., Frey et al. 2020; Aldrich and Lotito 2020), no study has, to our knowledge, taken into account the micro-level characteristics of decision-makers.

Specifically, research on the personality of political leaders strongly suggests that their personality drives their actions once in office (e.g., Lilienfeld et al., 2012; Rubenzer et al., 2000; Watts et al., 2013). Human behavior is driven by individual differences; that is, different individuals behave differently when facing similar situations. This assumption has been confirmed over the past decades in countless studies showing how human personality - "who we are as individuals" (Mondak 2010: 2) - shapes our social and political actions (e.g., Chirumbolo and Leone 2010; Gerber et al. 2011; Vecchione and Caprara 2009). Furthermore, leaders' personality traits have been portrayed as impacting their governments' 
policies (Greenstein 1998; Owen and Davidson 2009). Therefore, while it has been said that crises forge the character of leaders (e.g., Koehn, 2017), the reverse could also be true. In line with this proposition, the current analysis explores the following question: Do government leaders' personality traits impact policy responses to the COVID-19 crisis?

The current study therefore assesses the extent to which the personalities of 61 heads of government (i.e., presidents or prime ministers) explain the divergent responses to the COVID-19 crisis by regressing country-specific policy-responses (collected from Oxford COVID-19 Government Response Tracker initiative, henceforth, OxCGRT) against data on leaders' personality traits collected from a large-scale comparative expert survey measured before the onset of the pandemic (NEGex) (Nai, 2019), while controlling for important covariates. Our findings highlight the impact of two personality meta-traits "stability" (conscientiousness, agreeableness, emotional stability) and "plasticity" (extraversion, openness) - on both the magnitude and promptness of government responses. Ultimately, our findings support the assumption that the personality of the leader is likely to influence policy responses during a crisis, underscoring the need to account for this important, and generally overlooked, micro-level political factor in subsequent research focusing on outcomes of the COVID-19 pandemic and other similar crisis situations.

\section{Leaders, their personality, and policies}

Politicians play an important role in policy-making. Research has shown that the composition of legislatures, the characteristics of the politicians that sit in them, not only influences the topics that are debated (Saalfeld and Kyriakopoulou 2010), but also the actual policies that are ultimately enacted (Clayton and Zetterberg 2018). Political leaders also impact policies. Legislative politics has become quite leader-centric in terms of image and decision-making (McAllister 2007; Savoie 2008). The scholarship demonstrates that a change of leadership generally entails a shift in policy positions for political parties (Adams et al. 2004). This is often also the case for governments; even if the governing party remains the same, as the change from Theresa May to Boris Johnson in the United Kingdom and from Rafael Correa to Lenin Moreno in Ecuador arguably illustrate.

Scholars have theorized that the aspects that derive political leaders' capacity to influence policy reside around their personal backgrounds (e.g., Alexander and George 1956). Particularly, personality traits of leaders have been highlighted as being associated with specific policy directions undertaken by their governments (Greenstein 1998; Owen and Davidson 2009). Specifically, the partisan and ideological preferences of political elites have been shown to align along the Big Five Inventory (BFI) (Hanania 2017; Joly et al. 2018).

The BFI summarizes differences in human personality along five basic traits: extraversion (sociability, energy, charisma), agreeableness (cooperative and pro-social behaviors, conflict avoidance, tolerance, pleasantness), conscientiousness (discipline, responsibility, organization, dependability), emotional stability (calm, detachment, low emotional distress, low anxiety), and openness (curiosity, intelligence, 
and a tendency to make new experiences) (John and Srivastava 1999; McCrae and John 1992). Evidence from previous studies on the public at large and on political elites provides insights as to how these five personality traits of decision-makers could influence their response to a crisis (Seibert and Kraimer 2001; Graziano et al. 2007; Fredrickson et al. 2003; De Hoogh et al. 2005; Riolli et al. 2002). Indeed, the COVID19 crisis presents an opportunity to explore this assumption. Based on the scholarship that demonstrates that leaders not only impact policy-making but that their personality traits have an influence on policy outcomes, we expect that a leader's personality likely impacts the policy-responses enacted during the COVID-19 crisis in terms of both magnitude and promptness.

Furthermore, the scholarship points to a simplified schema of the personality of public figures around two traits: "stability" and "plasticity" (Caprara et al. 2007; Oltmanns et al. 2004). That is, the five separate personality traits of the BFI align into two broader macro-traits. DeYoung and colleagues (2006; 2007) discuss these two "higher-order factors". The first one includes converging agreeableness, conscientiousness, and emotional stability into what is termed the "stability" meta-trait. Based on research on agreeableness, conscientiousness, and emotional stability, the "stability" meta-trait would be associated with pro-social interactions, intelligence, and positive self-image (Hibbing et al. 2011; JensenCampbell et al. 2003; Hills and Argyle 2001). The second meta-trait, "plasticity" converges extraversion and openness, and would be associated with charismatic leadership and creativity (Bono and Judge 2004; Mondak and Halperin 2008).

Given the complex nature of the dynamics at play, we refrain from developing specific formal expectations for the effects of each of the two specific meta-traits. Nonetheless, existing evidence in social and political psychology literature suggests several avenues for potential effects. First, as a metatrait "stability" is associated with stronger scores on conscientiousness, agreeableness, and emotional stability. All these traits seem intuitively associated with a stronger response, but also potentially with a more cautious (i.e., delayed in time) approach. Conscientiousness is often linked with stronger achievement orientation (working hard and persistence in the pursuit of individual goals), dependability (strong organizational skills and general responsible behaviors), and a marked preference for projection and planning (Judge et al. 1999; Seibert and Kraimer 2001). Conscientious individuals perform well in challenging situations, where their discipline and proclivity for perseverance allows them to map and overcome the challenges they face (Hochwarter et al. 2000). At the same time, excessive conscientiousness "can be associated with obsessionality, perfectionism, rigidity and slowness to respond" (Furnham 2017: 1880). Agreeableness is positively associated with empathy and a stronger urge towards helping behaviors, and individuals high in this trait are "more willing to risk negative outcomes to help others in both ordinary and extraordinary situations" (Graziano et al. 2007: 587), including strangers. Finally, emotional stability has been frequently associated with higher resilience in times of crisis (Fredrickson et al. 2003; Riolli et al. 2002), but also with low impulsiveness (Stanford et al. 2003). The second meta-trait is associated with higher scores on openness an extraversion. Openness is positively associated stronger resilience in times of crisis (Fredrickson et al. 2003; Riolli et al. 2002), whereas extraversion is often associated with social dominance and disinhibition (e.g., Newman 1987), 
thus potentially with lower risk aversion. In this sense, this second trait could perhaps be associated in political leaders with a stronger and also a swifter response.

\section{Data And Methods}

We investigate the relationship between leader personality traits and their country's response to the COVID-19 crisis by triangulating independent evidence from two data sources. Data for the governments' response to the COVID-19 crisis is collected from the OxCGRT initiative. Data for the personality traits of political leaders comes from the NEGex expert survey (Nai, 2018). Combining these two datasets provides information on the heads of government (presidents or prime ministers) in 61 countries in power during the onset and initial months of the COVID-19 crisis in early 2020, as well as the policy responses that these countries enacted during the first wave of the pandemic (covering the time period from January $1^{\text {st }}$ to June $30^{\text {th }} 2020$, corresponding to a total of 26 weeks). Figure 1 illustrates the geographical coverage of our investigation. The list of all leaders included in our investigation and their personality profiles are reported in Table A1 (Appendix A).

\section{Government responses to the COVID-19 crisis}

In order to gauge the policy responses of countries during the pandemic, we rely, as others already have (Aldrich and Lotito 2020; Kavakli 2020; Frey et al. 2020), on the OxCGRT data, hosted by the Blavatnik School of Government at the University of Oxford (Hale et al. 2020). ${ }^{1}$ The OxCGRT dataset holds data on daily country-level policy responses of 170+ countries worldwide starting in January 2020. The policy response data includes several dimensions of the governments' responses to the pandemic. In the current analysis, we select three indicators as our dependent variables based on the extent to which the national leadership may influence these policies, as described in more detail below.

Given that the OxCGRT data bases the majority of their indicators on the most stringent government policy that is implemented in a country, the dataset applies policies implemented at the regional or local level to the entire country. Only two out of 18 indicators reported in the OxCGRT dataset are limited to policies exclusively enacted by national governments: restrictions on international travel and the implementation of debt/contract relief for households. The former records the presence of specific restrictions on international travel using a five-point ordinal scale: 0 (no measures in place), 1 (screenings), 2 (quarantine on arrivals from high-risk regions), 3 (ban on arrivals from some regions) and 4 (ban on all regions or total border closure). The latter, which we label as "Financial Relief", measures the extent of financial interventions provided to households, such as measures to stop loan repayments. It uses a three-point ordinal scale: 0 (no relief), 1 (narrow relief, specific to one kind of contract) and 2 (broad debt or contract relief). In summary, these two indicators directly measure national policy responses to external risk (e.g. arrival of infection from abroad) and towards internal citizen-centered difficulties (e.g. unemployment, domestic economic situation). 
Additionally, we also included a third indicator: the overall government response index. This composite index tallies countries' responses to all 18 indicators: the cancellation of public events, restriction in gatherings, stay-at-home requirements, restrictions on internal movement, testing policies, etc. This index broadly reflects the breadth of the governmental response to the crisis and has been standardized to vary between 0 (no measures taken) to 100 (maximum level). While this index applies policy decisions taken at the regional and local levels in a countrywide manner, we nevertheless decided that it would be important to investigate the impact of national leaders' personality on an overall policy response during such an extraordinary national emergency. Indeed, prior work has shown that central governments can impact the policy choices of sub-national units (Allen et al. 2004). Furthermore, recent research on central governments' response to COVID-19 has also utilized this OxCGRT indicator in such a manner (Aldrich and Lotito 2020; Kavakli 2020).

Moreover, for each of the three policy responses selected, we have used two different measures of responsiveness: (i) the average level of responsiveness in each country over the 26-week period under investigation (i.e. magnitude), and (ii) the rapidity of the response implemented by the government, measured as the total number of days at the minimum level on the indicator since January $1^{\text {st }}, 2020$ (i.e. promptness). ${ }^{2}$ Taken together, these two variables reflect, for each country, the average intensity of the government response, and the delay in initiating a response. Figures C1, C2 and C3 in the

Appendix display heat maps, which summarize the differences in the average responsiveness for all three interventions across the study time frame ( 26 weeks) for each country.

\section{Leaders and personality traits}

The personality traits of government leaders are the main independent variables under investigation. These data were ascertained from the NEGex dataset (Nai 2019). This dataset surveys a country-specific sample of scholars with expertise on elections and their country's politics. Expert are surveyed following each national election (since June 2016). ${ }^{3}$ Importantly for our purpose, the NEGex dataset includes variables that measure the personality traits of key candidates/party leaders for each election. For instance, for the 2016 US Presidential election experts were asked to evaluate the personality of both Donald Trump and Hillary Clinton. Experts were randomly assigned to either candidate (e.g., either Trump or Clinton), to ensure that their ratings do not reflect any direct comparison between the different personalities at play but only focus on one specific candidate. The NEGex questionnaire includes the Ten Items Personality Inventory (TIPI) (Gosling et al. 2003); experts were therefore asked to rate ten statements about the personality of the candidate (e.g., are they "critical, quarrelsome", "dependable, selfdisciplined") on a scale from 0 "very low" and 4 "very high." Pairs of statements, one positively and one negatively framed, reflect each of the five traits.

In terms of data validity for the measure of personality, several studies have shown significant crossobserver agreement - that is, external observers can rate the personality of other persons in a way that is 
consistent with the self-assessment of the latter (e.g., McCrae and Costa 1987; Moshagen et al. 2019). Evidence suggests that external observers also tend to agree with each other rather consistently (Vazire $2006,2010)$. This should be especially likely for figures that are as constantly in the public spotlight as political leaders. In the data, the average standard deviation across the five traits across all candidates that is, how much experts on average "converge" on the ratings they provided - is around 0.98 (personality variables range between 0 and 4). Experts seem to be slightly more consensual when it comes to the candidates' emotional stability $(S D=0.93)$, and slightly less consensual about the candidates' openness $(S D=1.03)$. Despite certain limitations, we are confident to rely on aggregated expert assessments, which provide a systematic, comparable, and reliable measurement of leaders' personality traits.

The personality traits of political leaders are not independent constructs. The results (see Table B1 in Appendix B) of principal component analysis show the existence of two orthogonal underlying personality dimensions, explaining respectively $49 \%$ (Dimension 1) and 32\% (Dimension 2) of the variance; in line with the findings of DeYoung (2006). The first dimension is characterized by strong scores on conscientiousness, agreeableness, and emotional stability, thus reflecting "stability". The second is characterized by high scores on extraversion and openness, reflecting "plasticity." We therefore computed two "meta-traits" additive indexes that reflect the two underlying dimensions (respectively, $a=$ 0.83 for stability and $a=0.73$ for plasticity).

The distribution of the 61 leaders in the current analysis on the two personality meta-traits (Figure B1 in the Appendix) shows that on average national leaders tend to score above the midpoint on both indicators. As an example, Donald Trump scores the lowest among all 61 candidates on stability, whereas Jacinda Ardern scores the highest. In terms of plasticity, Daniel Ortega scores the lowest across all candidates, and Justin Trudeau scores the highest among all candidates on this personality meta-trait.

\section{Control variables and models}

Our models adjust for political, demographic, health system, and economic characteristics that are likely associated with the policy responses to the pandemic. First, we adjusted for numerous sources of potentially important political and social variability. For instance, in line with results discussed by Kavakli (2020), our models adjust for an important political characteristic: populism. We identified whether the leaders are "populist" (or lead a populist party) or not, based on classifications from comparative literature (e.g., Mudde 2007; Albertazzi and McDonnell 2008) and existing inventories such as the PopuList (Rooduijn et al. 2019). We also adjust for regime type, which has been associated with differential responses to the COVID-19 crisis (Frey et al. 2020). More specifically, we control for the Combined Polity Score from the Polity Project - a composite index compiled by the Center for Systemic Peace and ranging from -10 (strongly autocratic) to +10 (strongly democratic). ${ }^{4}$ Moreover, the models additionally adjust for the cultural characteristics of countries. Specifically, as individualism has been demonstrated to have an impact on the evolution of the COVID-19 crisis (Dryhurst et al. 2020; Frey 
et al. 2020), we adjust for this cultural factor. The data on cultural characteristics of each country were collected using the Hofstede model (see Hofstede et al. 2010). ${ }^{5}$

Second, we have also controlled for factors that may reflect a country's ability to cope with the COVID-19 pandemic (i.e., demographics and health system strength), which can in turn influence policy responsiveness. More specifically, seeing that the pandemic has had its most severe impact on older populations, we adjust for the proportion of individuals aged 65 years and older, while also adjusting for differences in terms of health system capacity (i.e., number of hospital-beds per 1,000 individuals). We also adjust for the mortality (i.e., cumulative reported deaths per 10,000 individuals between from January 1 to June 30,2020), as well as the time elapsed since the identification of the first 100 cases until the end of the study time-frame (June 30,2020). These factors were adjusted for in order to account for differences in both the severity and the timing of the crisis across different countries that may influence the magnitude and timing of different policy responses. The data for health and pandemicrelated factors were all collected from the World Health Organization (WHO 2020).

Third, seeing that many of the policy responses have had profound economic implications during this period and given that the ability to implement certain measures will likely depend on a nation's fiscal capacity (Arellano et al. 2020), we also adjusted for the debt-to-GDP ratio of the national government. Data for this economic variable was collected from the International Monetary Fund (IMF 2018). Moreover, since travel restrictions have had a devastating impact on tourism (Nicola et al. 2020), we also accounted for a country's economic dependence on that industry while exploring the determinants of international travel controls. To do so, we used international tourism receipts (as a percentage of total exports) data from the World Bank (World Bank 2018).

Finally, as previously indicated, the overall government response outcomes include policies enacted at sub-national and national levels alike, necessitating an adjustment for the level of decentralization of countries included in the analysis. We collected data on the level of regional autonomy in each country from the Regional Authority Index (Hooghe et al. 2016). Specifically, to account for this, we use the n_policy variable, which is on a 5-pt scale that we interpret as ranging from 0 (highly centralized) to 4 (high decentralized).

Because the outcomes that are averages are continuous, we use OLS regressions to estimate the relationships between the magnitude of the response (average score) outcomes with the predictors. With respect to the promptness of the response (number of days at the minimum), we employ count regression models. Diagnostic tests strongly suggest that the alpha parameter for the regressions with the count outcomes is not zero; we therefore use negative binomial regression models rather than the Poisson regression models (see Cameron and Trivedi 2013). Furthermore, given the relatively small number of observations, missing data on predictors were also imputed using multiple imputation methods prior to 
the regression analyses. Descriptive statistics for all variables (dependent variables, personality traits, covariates) are presented in Table B2 in Appendix B.

\section{Results}

We present below results of linear and negative binomial models on the three indicators of government response: international travel controls, financial relief, and overall government response. For each policy response indicator, we estimated both its magnitude (average level) and promptness (number of days at minimum level).

\section{International Travel Controls}

The results, displayed in Figure 2, indicate that the personality of the government leaders does not have a statistical impact on the level of international travel controls implemented during the first wave of the pandemic by the national governments. This is consistent for both personality traits evaluated, "stability" and "plasticity", after having adjusted for control variables. While personality has no effect on international travel restrictions, four control variables present significant associations with the average outcome. The proportion of elderly in the population is shown to have a negative and statistical (at $p<$ 0.05) impact; indicating the greater the proportion of residents over the age of 65 the weaker the average restrictions on international travel. Also, the days since the first 100 positive cases is shown to have a positive and significant (at $p<0.1)$ relationship. This suggests that the countries that reach this milestone at an earlier point in time implemented on average stronger restrictions on international travel. Further, we find that the regime type is also significantly (at $p<0.1$ ) associated with this outcome, with more democratic countries having implemented stronger travel controls.

As for the time taken to initiate a policy response on travel, the results displayed in Figure 2 (bottom panel) show that mortality rate, the number of hospital beds per 1,000 individuals, the proportion of elderly, and the regime type were the only variables to present a significant relationship with the timing of international travel restrictions. In brief, countries with a greater hospital bed capacity and a greater level of democracy implemented international travel restrictions with significantly (both at $p<0.05$ ) less delay. Whereas, the mortality rate and the proportion of elderly in a country coincides with statistically (both at $p$ $<0.1)$ longer time to implement international travel controls.

The findings of our analyses on international travel controls do allow for a better understanding of the factors that account for governments' restrictions on international travel. However, in terms of the personality of government leaders, the results do not provide evidence that personality has contributed to the magnitude or promptness of international travel restrictions that were adopted by countries during this crisis.

\section{Financial Relief}


In contrast to the finding on international travel, we find that the personality of government leaders does indeed have a statistical impact on the average financial relief policies implemented by countries during the first wave of the pandemic, as displayed in Figure $\mathbf{3}$ (top panel). Firstly, the "stability" personality trait is shown to have a statistical (at $p<0.05$ ) and positive relation with financial relief policies. The higher that a leader scored on this trait the more financial help their government provided to its citizens. To better assess the magnitude of this relationship, predicted probabilities were computed and are displayed in Figure B2 in Appendix B. The results show that moving from the low end of the "stability" scale to the high end leads to a rather considerable 0.71-pt (on a 3-pt scale) increase in the average financial relief that was provided by countries. For its part, the "plasticity" personality trait is not shown to be statistically related to the average financial relief. The only other variable that is demonstrated to have a statistical (at $p<0.1)$ relationship with the average level of financial relief is the proportion of elderly in the population; indicating that a larger elderly population is associated with greater financial assistance offered by governments to their citizens.

As for the second outcome of financial relief, the findings, in Figure 3 (bottom panel), demonstrate that both personality meta-traits have a negative and significant (both at $p<0.1$ ) relationship with the time taken to provide financial relief to citizens. Countries with leaders who score high on both of these attributes, were quicker in providing financial aid to citizens. Essentially, these countries appear to have been more willing to address their populations' financial difficulties during the COVID-19 crisis. Figure B3

in Appendix B displays the substantive impact that both personality traits have on this outcome. These results show that countries with a leader who scored at the highest end of these personality traits, compared to those who score at the lowest end of the scales, had respectively for "stability" and "plasticity" 53 and 42 less days without any financial relief. Therefore, both personality traits of the government leaders are shown to have a rather important impact on the actions that a country took to financially assist its population.

With respect to the control variables, both mortality and the proportion of elderly in the population are shown to have a negative and significant (respectively at $p<0.1$ and at $p<0.05$ ) relationship with the amount of delay in initiating a financial relief response. Therefore, countries with an older population and those that incurred a higher death rate were more likely to provide financial assistance to their citizens during the pandemic.

Contrary to international travel controls, the findings clearly support the notion that government leaders' personality has an impact on the financial relief policies. In brief, countries with leaders that score higher in "stability" and "plasticity" appeared to be more willing to address their populations' financial difficulties during the first wave of the COVID-19 crisis. $^{6}$

\section{Overall Government Response}

As in the case of financial relief, we find that the personality of government leaders is also associated with the overall government response towards the COVID-19 crisis. The analysis of the average overall 
government response, in Figure 4 (top panel), demonstrate that the "plasticity" personality trait is statistically related (at $p<0.05$ ) in a positive manner to policies enacted by a country. In other words, a country in which the leader scores high on the "plasticity" trait is more likely to have greater average government intervention in response to the COVID-19 crisis. Predicted probabilities, see Figure B4 in Appendix B, show that going from the low end of the "stability" scale to the high end leads to a 16-pt increase on the average overall government response. However, no statistical relationship is shown for the "stability" personality trait. In fact, "plasticity" is the only variable that demonstrates a significant relationship with this outcome.

Because the overall government response metric applies the most stringent policies countrywide, this parameter can reflect decision-making at the regional or local levels alike. It is, therefore, necessary to verify the moderating role of decentralization on the impact that the national leaders' personality may have on the average overall government response outcome. Essentially, this relationship should be more pronounced in centralized countries since the national governments of such countries are directly responsible for a larger range of policies. Indeed, the results in Figure $\mathbf{5}$ support this assertion. The "plasticity" personality trait of government leaders from highly centralized countries has, from the low end of the stability scale to the high end, a 17-pt and significant (at $p<0.05$ ) increase on the average overall government response. While the same relationship is also present in highly decentralized countries, it is much smaller and not significant. Therefore, the impact of national-level leadership is much more pronounced in more centralized countries, as expected. These results ultimately support the use of the overall government response variables in our analyses and further strengthens the proposition that policy-makers' personality type can directly influence decision-making during a national emergency.

As for the promptness of the overall government response, neither of the personality traits demonstrate a significant relationship with this outcome (Figure 4, bottom panel). The only variables in the model to do so are mortality and the level of decentralization (both at $p<0.1$ ). A higher mortality corresponds with a more rapid overall government response. This relationship seemingly points to a reactive characteristic of governments towards the number of deaths amongst their population. In terms of decentralization, a greater level of decentralization is also associated with quicker overall government response. This result is in line with the fact that the dependent variable includes policies implemented at both the regional and local levels of government; therefore, the more decentralized a country is the more opportunities exist to implement a policy in response to the COVID-19 crisis, resulting in fewer days on record without any response at all in these types of countries, in general.

The analyses of the overall government response do support the assertion that the personality of the leaders can impact the overall policies that have been implement in response to the COVID-19 crisis. Albeit, this appears to be moderated by the extent to which different levels of government are involved in decision-making vis-à-vis national leadership. Moreover, only "plasticity" is shown to have a statistical relationship with only one of the two outcomes; this may be related to the promptness measure being unduly influenced by the different levels of decentralization across countries. 
Ultimately, this series of analyses demonstrate that the personality traits of government leaders have had an impact on the policy responses during the first wave of the COVID-19 pandemic. While the findings do not show a ubiquitous impact of government leaders' personality on COVID-19 related policies, they show nonetheless that leaders scoring high on "plasticity" provided a stronger response in general (average overall response). Such leaders also provided a swifter response to the pandemic in terms of debt relief, while "stable" leaders displayed both a stronger and more rapid response on this dimension.

\section{Robustness checks and further analyses}

Seeing as presidential systems can be more leader-focused, it is plausible that the personality of a president may have a greater impact on policies than that of a prime minister. To test this assertion, we investigated the potential moderating role of the system of government on the relationships between personality and the policy responses that were found to be significant in the previous analyses. We found a single significant moderating relationship. Figure B5 in the Appendix shows that "stability" of presidents, from the low end of the "stability" scale to the high end, corresponds to a rather strong and significant (at $p<0.05$ ) increase on the average financial relief provided by governments; whereas no statistical relationship is shown for prime ministers. These results highlight that the personality of leaders in a presidential system has more influence on responses to the pandemic than that of leaders in a parliamentary system. However, out of the four associations between the leaders' personality traits and the policy responses that were identified as significant, this is the only one for which the system of government demonstrates a statistical moderating relationship.

Furthermore, while the sex of politicians has been linked to different policy outcomes (Clayton and Zetterberg 2018), research has so far failed to identify a relationship between the sex of the national leader and policy responses to the COVID-19 crisis (Aldrich and Lotito 2020). We nevertheless decided to adjust for the sex of the government leaders. The results (not reported) are essentially the same for the personality traits. The only exception is that the relationship between the "plasticity" personality trait and the number of days without any overall government response becomes significant (at $p=0.1$ ).

Finally, the personal preferences of the experts used to ascertain the personality trait might impact the accuracy of their evaluation. Though Nai and Maier (2019) have shown that the experts tend to be substantially less influenced by their political preferences than voters, we nevertheless erred on the side of caution and computed "adjusted" measures of candidates' personality traits to account for experts' personal bias (see Walter and Van der Eijk 2019). ${ }^{7}$ These measures are net of the ideological distance between the average expert and the candidate they had to evaluate. The adjusted measures for the Big Five personality traits also loaded in a similar manner on two orthogonal meta-traits. We performed all of the analyses with the "adjusted" personality meta-traits and the findings (not reported) for the two personality traits are essentially the same.

In summary, the results support that personality has had an impact on the policy responses enacted towards the pandemic. While not all of the policy responses demonstrate a relationship with the two 
personality traits, there are several statistical associations between government leader's personality traits and policy responses that supports their importance. Essentially, our results highlight the important effects that leaders' personality has had on the policy responses to the COVID-19 crisis.

\section{Discussion And Conclusion}

During the first six months of the COVID-19 pandemic, general observers have drawn comparisons between world leaders' responses to the COVID-19 pandemic and their character (e.g., Mkhondo 2020; Taylor 2020). Much has been written for example about the lackluster response of the US government to the crisis, from repeated denials about the gravity of the situation to late testing protocols and the absence of precise behavioral recommendations (e.g., Yong 2020). In the case of Germany, its ability to avert the high mortality seen in some of its European neighbors has been specifically attributed to Angela Merkel (Miller 2020). The comparative ineffectiveness of the US in handling the COVID-19 crisis has also been attributed to its leadership (e.g., Tomasky 2020). However, the plausible influence of leaders' personality on policy responsiveness towards the COVID-19 crisis has never been empirically assessed. In this study, we tackle this scholarly gap and explore the extent to which the initial policy response to the pandemic has been shaped by the personality traits of current world leaders.

Specifically, we investigated the relationship between leaders' personality and policy responses towards the COVID-19 crisis by triangulating evidence on government responsiveness during the first-wave (1 January, 2020 to 30 June, 2020) of the pandemic (OxCGRT) and data from the NEGex comparative expert survey (Nai, 2019), which allows to map the personality profile of current heads of government (measured before the onset of the pandemic). Controlling for important macro-level covariates expected to drive the country response to the crisis, and focusing particularly on two personality meta-traits - "stability" (conscientiousness, agreeableness, emotional stability) and "plasticity" (extraversion, openness) - our models show that the individual personality of political leaders matter.

In brief, our analyses indicate that leaders scoring high on "plasticity" tend to provide stronger overall responses (average). Such leaders also respond more rapidly in terms of debt relief policies, as do "stable" leaders. Similarly, "stable" leaders also offer a stronger response in terms of debt relief. However, we do not find any evidence that leaders' personality is related to the implementation of travel restrictions; indicating that personality may impact certain types of policy-decisions more than others. While the findings do not show a ubiquitous impact of government leaders' personality on COVID-19 related policies, they are generally consistent with the overall expectation that governments' response to the COVID-19 crisis is related to their leaders' personality.

From a theoretical standpoint, our results deepen our understanding of the areas in which the personality of leaders is likely to matter. Growing evidence shows that the performance of elected officials is, in part, driven by their personality profile (Ramey et al. 2017; Watts et al. 2013). In terms of policy, while research has previously highlighted the importance of leaders' personality on government policies (e.g., Greenstein 1998; Owen and Davidson 2009), this scholarship is surprisingly rather limited. Our results are therefore 
generally consistent with findings that demonstrate the importance of politicians' personality regarding their political behavior, and underscore the importance of individual differences in national leadership with respect to policy-making, specifically in response to a crisis. Therefore, studies that focus on crises such as global climate change, the depletion of natural resources, mass refugee migration, etc. - need to consider the role of the personality of political elites in order to develop a thorough understanding of such phenomena.

From a practical standpoint, our analyses suggest that studies, which investigate policy decisionsmaking should account for the potential impact that the personal attributes of decision-makers may have on policy decisions, in conjunction with more the commonly examined structural, political, and social factors. If, as we have shown in the current study, differences in the personality of political leaders can alter the trajectory of governmental responses to such a global crisis, then the medium- and long-term consequences of the COVID-19 crisis itself will be, at least in part, a function of these personality differences. To be sure, the personality of leaders cannot be expected to have an overarching direct effect on policy; even when assuming that leaders can dictate policies directly, many factors come into play during implementation. Nonetheless, we demonstrate that the personality of the leader is likely to influence the policies set in place; either because their character influences the overall style of the administration, or because local leaders, bureaucrats and civil servants may align with the leader to signal allegiance. Regardless of the specific mechanisms at play, which are beyond the scope of our investigation, good reasons exist in expecting an association between a leader's personality and the outputs of their government.

Further, our findings also highlight an important methodological point, particularly with respect to the use of OxCGRT data. We demonstrate that the overall government response index is in fact conditional on the level of decentralization in a given country. For instance, we find that the relationship between the "plasticity" meta-trait and the average overall government response is moderated by the level of decentralization. While the OxCGRT data is frequently used to inform a rapidly expanding body of evidence around the COVID-19 pandemic, to our knowledge no study has yet explored the impact of decentralization on OxCGRT indicators, which code sub-national policies in a countrywide manner. Therefore, all future research exploring the relationship of almost all the OxCGRT indicators (except international travel restrictions and financial relief) should account for the level of decentralization of each country.

Similarly, we also find differences in the moderating influence of the system of government, albeit limited. While the personality of presidents is shown to moderate the relationship between the stability meta-trait and the average financial relief, the analyses do not point to any other statistical difference between presidents and prime ministers. Substantively, replacing a government leader with the "wrong" personality attributes is arguably easier in a parliamentary system than a presidential one (especially in countries such as Australia). Although institutional and political barriers might complicate the process to change a head of government, future research should nevertheless endeavor to explore which "types" of leader persevere or fall during crises. 
Still, while our research provides novel and interesting insights into how a national leader's personality may influence decision-making during a national emergency, the study does have its limitations. The findings likely reflect conservative estimates because a leader's personality cannot be expected to singlehandedly drive government policies - especially in terms of complex and multifaceted crises such as the COVID-19 pandemic. Furthermore, the exact mechanisms that explain why certain meta-traits impacted specific policy responses but not others remain unknown. Specifically, we cannot theoretically or empirically isolate the reasons that led to international travel restrictions being independent of government leaders' personality traits.

Moreover, though we argue for the importance of considering micro-level political factors such as personality in subsequent investigations, exploring politicians' personalities is ripe with difficulties. While self-reported survey data from the politicians themselves might be the standard (e.g., Joly et al. 2018; Scott and Medeiros 2020; Schumacher and Zettler 2019), this approach becomes unrealistic for largescale comparative studies. Furthermore, it is unlikely that high-profile political leaders - presidential candidates, party leaders, prime ministers, and so forth - would agree to volunteer their insights into their own personality; the chances to get leaders the like of Donald Trump, Benjamin Netanyahu, Boris Johnson or Jair Bolsonaro to answer a questionnaire are virtually non-existent. As an alternative to selfreports, recent work has been developed to estimate the personality of political figures via the systematic analysis of secondary data, such as parliamentary speeches, by implementing machine learning techniques (Ramey et al. 2017). We, however, highly recommend the usage of experts' surveys, as we have done so in this study. This is a proven technique that allows to relatively easily and reliably measure politicians' personality (Nai and Maier 2018; Visser et al. 2017; Nai and Martinez i Coma 2019). However, regardless of the technique used to measure personality traits in leaders, our study demonstrates that scholars should account for such political factors when exploring policy-making, especially in times of crisis.

Finally, while it is beyond the scope of our investigation to quantify the effects of leaders' personalities on the health and economic consequences of the crisis (e.g., causalities, magnitude of the economic downturn, etc.), we nevertheless believe that future research should explore these relationships as well. Since the character of leaders can partly drive the initial responses to the crisis, the leaders themselves can even be seen as somewhat responsible for these undesirable effects. Thus, who is in charge during a crisis matters and these phenomena should be thoroughly explored.

Specifically, regarding the COVID-19 crisis, our study is a glimpse into the predictors of policy responses for the first initial phase of the pandemic. As this crisis continues for, at least, the near future and evolves around the world, research will have to be careful to account for the manner in which the influence of predictors of specific outcomes might be conditioned to specific phases of the pandemic. Yet, regardless of how this crisis evolves, the personality of government leaders should be at the forefront of our understanding of the policies that are put forth. 


\section{Declarations}

Conflict of interest: M.Medeiros, A.Nai, A.Erman and E.Young declare that they have no conflict of interest.

\section{References}

Adams, James, Michael Clark, Lawrence Ezrow, and Garrett Glasgow. 2004. "Understanding change and stability in party ideologies: do parties respond to public opinion or to past election results?" British Journal of Political Science 34 (4):589-610.

Albertazzi, Daniele, and Duncan McDonnell. 2008. Twenty-first century populism: The spectre of Western European democracy. Houndmills: Palgrave.

Aldrich, Andrea S., and Nicholas J. Lotito. 2020. "Pandemic Performance: Women Leaders in the Covid-19 Crisis." Politics \& Gender.1-9.

Alexander, L., and Juliette L. George. 1956. Woodrow Wilson and Colonel House. New York: Dover.

Allen, Mahalley D., Carrie Pettus, and Donald P. Haider-Markel. 2004. "Making the national local: Specifying the conditions for national government influence on state policymaking." State Politics \& Policy Quarterly 4 (3):318-44.

Arellano, Cristina, Yan Bai, and Gabriel P. Mihalache. 2020. "Deadly Debt Crises: COVID-19 in Emerging Markets." Cambridge: National Bureau of Economic Research.

Bono, Joyce E., and Timothy A. Judge. 2004. "Personality and transformational and transactional leadership: a meta-analysis." Journal of applied psychology 89 (5):901.

Cameron, A. Colin, and Pravin K. Trivedi. 2013. Regression analysis of count data. Cambridge Cambridge university press.

Caprara, G. V., C. Barbaranelli, R. Chris Fraley, and M. Vecchione. 2007. "The simplicity of politicians' personalities across political context: An anomalous replication." International Journal of Psychology 42 (6):393-405.

Chirumbolo, Antonio, and Luigi Leone. 2010. "Personality and politics: The role of the HEXACO model of personality in predicting ideology and voting." Personality and Individual Differences 49 (1):43-8.

Clayton, Amanda, and Pär Zetterberg. 2018. "Quota shocks: Electoral gender quotas and government spending priorities worldwide." The Journal of Politics 80 (3):916-32.

De Hoogh, Annebel H. B., Deanne N. Den Hartog, and Paul L. Koopman. 2005. "Linking the Big FiveFactors of personality to charismatic and transactional leadership; perceived dynamic work environment 
as a moderator." Journal of Organizational Behavior: The International Journal of Industrial, Occupational and Organizational Psychology and Behavior 26 (7):839-65.

DeYoung, Colin G. 2006. "Higher-order factors of the Big Five in a multi-informant sample." Journal of personality and social psychology 91 (6):1138.

Dryhurst, Sarah, Claudia R. Schneider, John Kerr, Alexandra L. J. Freeman, Gabriel Recchia, Anne Marthe Van Der Bles, David Spiegelhalter, and Sander van der Linden. 2020. "Risk perceptions of COVID-19 around the world." Journal of Risk Research:1-13.

Fredrickson, Barbara L., Michele M. Tugade, Christian E. Waugh, and Gregory R. Larkin. 2003. "What good are positive emotions in crisis? A prospective study of resilience and emotions following the terrorist attacks on the United States on September 11th, 2001." Journal of personality and social psychology 84 (2):365.

Frey, Carl Benedikt, Chinchih Chen, and Giorgio Presidente. 2020. "Democracy, Culture, and Contagion: Political Regimes and Countries Responsiveness to Covid-19." Covid Economics 18:1-20.

Furnham, Adrian. 2017. "The dark side of conscientiousness." Psychology 8 (11):1879-93.

Gerber, Alan S., Gregory A. Huber, David Doherty, and Conor M. Dowling. 2011. "The big five personality traits in the political arena." Annual Review of Political Science 14:265-87.

Gosling, Samuel D., Peter J. Rentfrow, and William B. Swann Jr. 2003. "A very brief measure of the BigFive personality domains." Journal of research in personality 37 (6):504-28.

Graziano, William G., Meara M. Habashi, Brad E. Sheese, and Renée M. Tobin. 2007. "Agreeableness, empathy, and helping: A person× situation perspective." Journal of personality and social psychology 93 (4):583.

Greenstein, Fred I. 1998. "The impact of personality on the end of the Cold War: A counterfactual analysis." Political psychology 19 (1):1-16.

Hale, T., N. Angrist, E. Cameron-Blake, L. Hallas, B. Kira, S. Majumdar, A. Petherick, T. Phillips, H. Tatlow, and S. Webster. 2020. "Variation in Government Responses to COVID-19. Version 7.0. ." ed. B. S. o. Government. Oxford.

Hanania, Richard. 2017. "The personalities of politicians: A big five survey of American legislators." Personality and Individual Differences 108:164-7.

Hibbing, Matthew V., Melinda Ritchie, and Mary R. Anderson. 2011. "Personality and political discussion." Political Behavior 33 (4):601-24. 
Hills, Peter, and Michael Argyle. 2001. "Emotional stability as a major dimension of happiness." Personality and Individual Differences 31 (8):1357-64.

Hochwarter, Wayne A., L. A. Witt, and K. Michele Kacmar. 2000. "Perceptions of organizational politics as a moderator of the relationship between consciousness and job performance." Journal of applied psychology 85 (3):472.

Hofstede, G., G. J. Hofstede, and M. Minkov. 2010. "Cultures and Organizations, Software of the mind. Intercultural Cooperation and Its Importance for survival." New York: McGraw-Hill.

Hooghe, Liesbet, Gary Marks, Arjan H. Schakel, S. Chapman Osterkatz, Sara Niedzwiecki, and Sarah ShairRosenfield. 2016. "A postfunctionalist theory of governance. Volume I: measuring regional authority." Oxford: Oxford University Press.

IMF. 2018. "Central Government Debt." ed. I. M. Fund. Washington D.C.

Jensen-Campbell, Lauri A., Katie A. Gleason, Ryan Adams, and Kenya T. Malcolm. 2003. "Interpersonal conflict, agreeableness, and personality development." Journal of personality 71 (6):1059-86.

John, Oliver P., and Sanjay. Srivastava. 1999. "The Big Five trait taxonomy: History, measurement, and theoretical perspectives." Handbook of personality: Theory and research 2 (1999):102-38.

Joly, Jeroen K., Joeri Hofmans, and Peter Loewen. 2018. "Personality and party ideology among politicians. A closer look at political elites from Canada and Belgium." Frontiers in psychology 9:552.

Judge, Timothy A., Chad A. Higgins, Carl J. Thoresen, and Murray R. Barrick. 1999. "The big five personality traits, general mental ability, and career success across the life span." Personnel psychology $52(3): 621-52$.

Kavakli, Kerim Can. 2020. "Did Populist Leaders Respond to the COVID-19 Pandemic More Slowly? Evidence from a Global Sample." working paper.

MacGregor-Fors, lan, and Mark E. Payton. 2013. "Contrasting diversity values: statistical inferences based on overlapping confidence intervals." PloS one 8 (2).

McAllister, lan. 2007. "The personalization of politics." In The Oxford handbook of political behavior, ed. R. J. Dalton and H. D. Klingemann. Oxford: Oxford University Press.

McCrae, Robert R., and Paul T. Costa. 1987. "Validation of the five-factor model of personality across instruments and observers." Journal of personality and social psychology 52 (1):81.

McCrae, Robert R., and Oliver P. John. 1992. "An introduction to the five-factor model and its applications." Journal of personality 60 (2):175-215. 
Miller, Saskia. 2020. "The Secret to Germany's COVID-19 Success: Angela Merkel Is a Scientist." The Atlantic, 20 April.

Mkhondo, Rich. 2020. "How Covid-19 has exposed the characters and communication skills of some world leaders." News24, 3 May.

Mondak, Jeffery J. 2010. Personality and the foundations of political behavior. New York: Cambridge University Press.

Mondak, Jeffery J., and Karen D. Halperin. 2008. "A framework for the study of personality and political behaviour." British Journal of Political Science:335-62.

Moshagen, Morten, Isabel Thielmann, Benjamin E. Hilbig, and Ingo Zettler. 2019. "Meta-analytic investigations of the HEXACO Personality Inventory (-Revised)." Zeitschrift für Psychologie 227 (3):18694.

Mudde, Cas. 2007. Populist Radical Right Parties in Europe. New York: Cambridge University Press.

Nai, Alessandro. 2019. "Disagreeable narcissists, extroverted psychopaths, and elections: A new dataset to measure the personality of candidates worldwide." European Political Science 18 (2):309-34.

Nai, Alessandro, and Jürgen Maier. 2018. "Perceived personality and campaign style of Hillary Clinton and Donald Trump." Personality and Individual Differences 121:80-3.

---. 2019. "Can anyone be objective about Donald Trump? Assessing the personality of political figures." Journal of Elections, Public Opinion and Parties.

Nai, Alessandro, and Ferran Martinez i Coma. 2019. "The personality of populists: provocateurs, charismatic leaders, or drunken dinner guests?" West European Politics 42 (7):1337-67.

Newman, Joseph P. 1987. "Reaction to punishment in extraverts and psychopaths: Implications for the impulsive behavior of disinhibited individuals." Journal of research in personality 21 (4):464-80.

Nicola, Maria, Zaid Alsafi, Catrin Sohrabi, Ahmed Kerwan, Ahmed Al-Jabir, Christos losifidis, Maliha Agha, and Riaz Agha. 2020. "The socio-economic implications of the coronavirus pandemic (COVID-19): A review." International journal of surgery 78:185.

Owen, David, and Jonathan Davidson. 2009. "Hubris syndrome: An acquired personality disorder? A study of US Presidents and UK Prime Ministers over the last 100 years." Brain 132 (5):1396-406.

Ramey, Adam J., Jonathan D. Klingler, and Gary E. Hollibaugh Jr. 2017. More than a feeling: Personality, polarization, and the transformation of the US Congress. Chicago: University of Chicago Press.

Riolli, Laura, Victor Savicki, and Ariana Cepani. 2002. "Resilience in the face of catastrophe: Optimism, personality, and coping in the Kosovo crisis." Journal of applied social psychology 32 (8):1604-27. 
Rooduijn, Matthijs, Stijn Van Kessel, Caterina Froio, Andrea Pirro, Sarah De Lange, Daphne Halikiopoulou, Paul Lewis, Cas Mudde, and Paul Taggart. 2019. "The PopuList: An overview of populist, far right, far left and Eurosceptic parties in Europe."

Saalfeld, Thomas, and Kalliopi Kyriakopoulou. 2010. "Presence and behaviour: black and minority ethnic MPs in the British House of Commons." In The Political Representation of Immigrants and Minorities: Voters, parties and parliaments in liberal democracies, ed. K. Bird, T. Saalfeld and A. M. Wüst. London: Routledge.

Savoie, Donald J. 2008. Court government and the collapse of accountability in Canada and the United Kingdom. Toronto: University of Toronto Press.

Schumacher, Gijs, and Ingo Zettler. 2019. "House of cards or west wing? self-reported hexaco traits of danish politicians." Personality and Individual Differences 141:173-81.

Scott, Colin, and Mike Medeiros. 2020. "Personality and political careers: What personality types are likely to run for office and get elected?" Personality and Individual Differences 152:109600.

Seibert, Scott E., and Maria L. Kraimer. 2001. "The five-factor model of personality and career success." Journal of vocational behavior 58 (1):1-21.

Stanford, Matthew S., Rebecca J. Houston, Charles W. Mathias, Nicole R. Villemarette-Pittman, Laura E. Helfritz, and Sarah M. Conklin. 2003. "Characterizing aggressive behavior." Assessment 10 (2):183-90.

Taylor, Paul. 2020. "Coronavirus brings out best (and worst) in world leaders." Politico, 25 March.

Tomasky, Michael. 2020. "This Is a Man-Made Disaster, and That Man Is Donald Trump." Daily Beast, 27 March.

Vazire, Simine. 2006. "Informant reports: A cheap, fast, and easy method for personality assessment." Journal of research in personality 40 (5):472-81.

---. 2010. "Who knows what about a person? The self-other knowledge asymmetry (SOKA) model." Journal of personality and social psychology 98 (2):281.

Vecchione, Michele, and Gian Vittorio Caprara. 2009. "Personality determinants of political participation: The contribution of traits and self-efficacy beliefs." Personality and Individual Differences 46 (4):487-92.

Visser, Beth A., Angela S. Book, and Anthony A. Volk. 2017. "Is Hillary dishonest and Donald narcissistic? A HEXACO analysis of the presidential candidates' public personas." Personality and Individual Differences 106:281-6.

Walter, Annemarie S., and Cees Van der Eijk. 2019. "Measures of campaign negativity: comparing approaches and eliminating partisan bias." The International Journal of Press/Politics 24 (3):363-82. 
Watts, Ashley L., Scott O. Lilienfeld, Sarah Francis Smith, Joshua D. Miller, W Keith Campbell, Irwin D. Waldman, Steven J. Rubenzer, and Thomas J. Faschingbauer. 2013. "The double-edged sword of grandiose narcissism: Implications for successful and unsuccessful leadership among US presidents." Psychological Science 24 (12):2379-89.

WHO. 2020. "Global Health Observatory data repository." ed. W. H. Organization. Geneva.

World Bank. 2018. "International tourism, receipts (\% of total exports)." ed. T. W. Bank. Washington D.C.

Yong, Ed. 2020. "America Is Trapped in a Pandemic Spiral." The Atlantic, 13 September.

\section{Notes}

[1] For more information on the project and the data: https://www.bsg.ox.ac.uk/research/researchprojects/coronavirus-government-response-tracker

[2] This variable intends to measure the number of days that the country stays at the minimum level of response since Jan 1, 2020, hence is a proxy for how quickly (or, slowly) the country moved away from 'zero' response. In three cases (Serbia and Nicaragua for Travel Restrictions; and Philippines for Financial Relief), countries have reverted back to 'zero' after a period of responsiveness, making these cases potential outliers, different from the rest. To account for this, we have run robustness checks by excluding these outliers from the specific models. Findings were robust to the exclusion of these cases, ensuring that their inclusion in the main models do not alter the results. Also, days at maximum response-level was not selected as an outcome due to possibility of censoring (i.e., certain countries may not have reached the maximum response level for all policy types during the study timeframe ending in June 30, 2020).

[3] On average, 6.2 experts provided personality ratings per leader. Scholars in the dataset tended to lean left-of-center $(M=4.26 / 10, S D=1.78), 76 \%$ were native to the country they resided in, and $28 \%$ were female. Overall, experts were very familiar with the elections (self-rating, $M=8.19 / 10, S D=1.66$ ). Importantly, the leaders' personality traits included in the dataset are measured before the COVID-19 crisis, thus ensuring the absence of endogenous effects between how leaders handled the crisis and their assessed personality. One exception is Leo Varadkar, who was Irish Prime Minister at the beginning of the COVID-19 crisis. The NEGex expert survey data was collected after the February 8, 2020 election in the Republic of Ireland; thus, within the period under investigation in this study (January 1- June 30, 2020). However, the election took place several weeks prior to the first recorded COVID-19 case in that country (February 29, 2020).

[4] For more information: http://www.systemicpeace.org/polityproject.html.

[5] Data available at: https://geerthofstede.com/research-and-vsm/dimension-data-matrix/.

[6] The data on financial relief stand out for Spain, see Figure C2 in the Appendix. We therefore performed the analyses with the financial relief outcomes excluding Spain. The results (not reported) show 
essentially no difference for the personality traits, with the exception that the relationships between the personality traits and days at minimum changing in significance level from $p<0.1$ to $p<0.05$.

[7] For each candidate in the dataset, we have regressed their scores on the five personality traits on the difference between their partisan identification and the average expert left-right position (that is, how "ideologically distant" the expert sample and the candidate they evaluated are). In a second step, we have saved the regression residuals - that is, the part of the dependent variable (personality traits) that is not explained by such ideological distance - into new variables. We have, in other terms, computed measures of candidates' personality traits that are independent of the ideological distance between the (average) expert and the candidates themselves - "the perception from which partisan biases have been eliminated" (Walter and Van der Eijk 2019: 372).

\section{Figures}

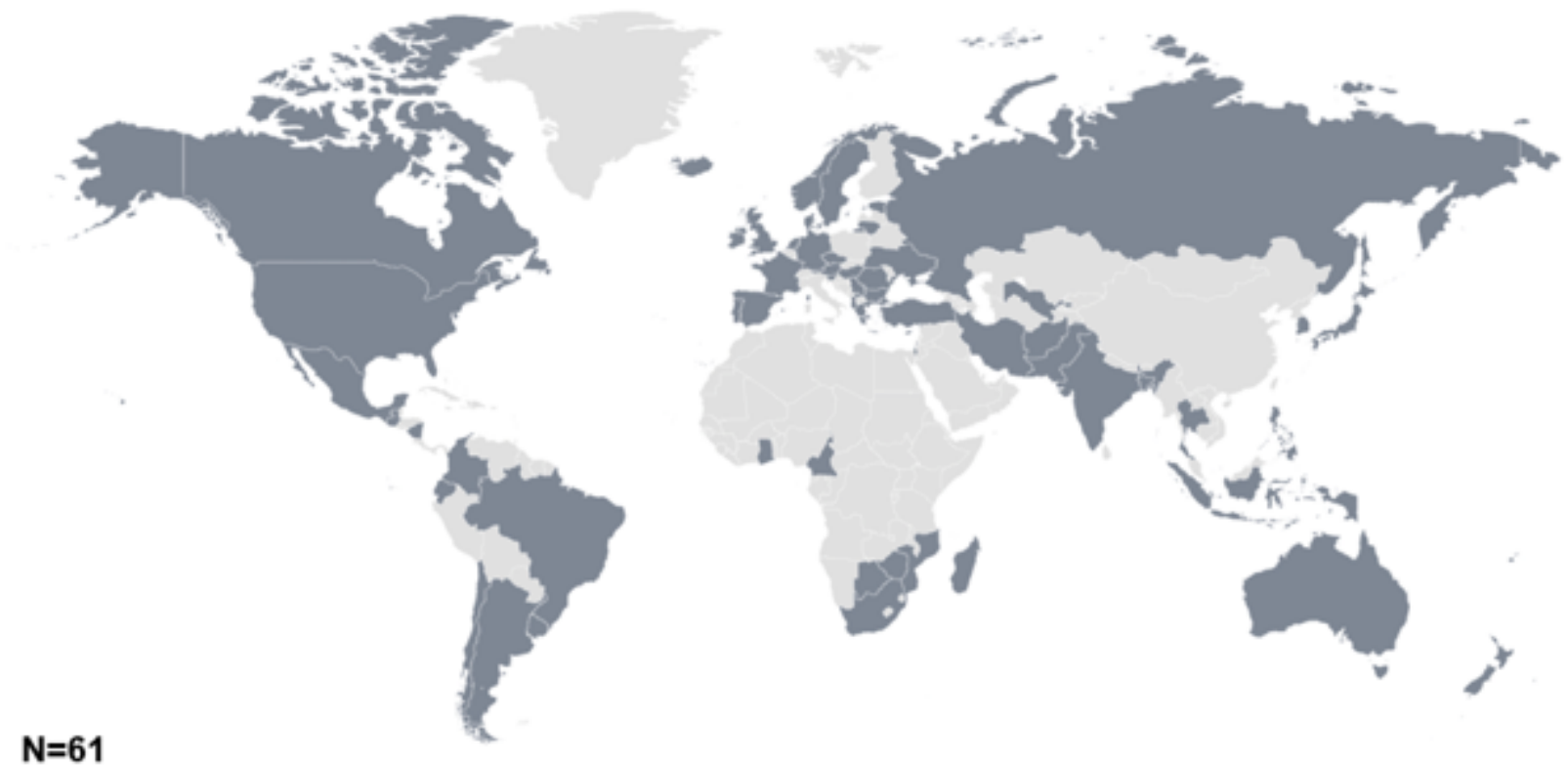

\section{Figure 1}

Geographical Coverage of Study. Note: The designations employed and the presentation of the material on this map do not imply the expression of any opinion whatsoever on the part of Research Square concerning the legal status of any country, territory, city or area or of its authorities, or concerning the delimitation of its frontiers or boundaries. This map has been provided by the authors. 
Figure 2. Determinants of International Travel Controls

(a) Magnitude (average score)

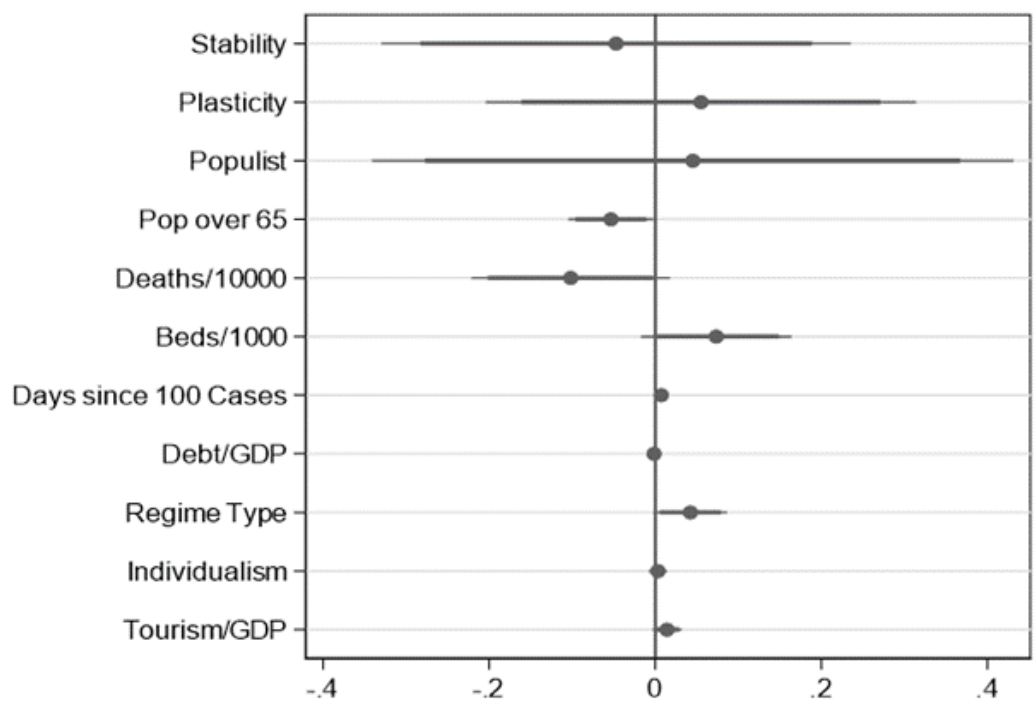

(b) Promptness (number of days at minimum value)

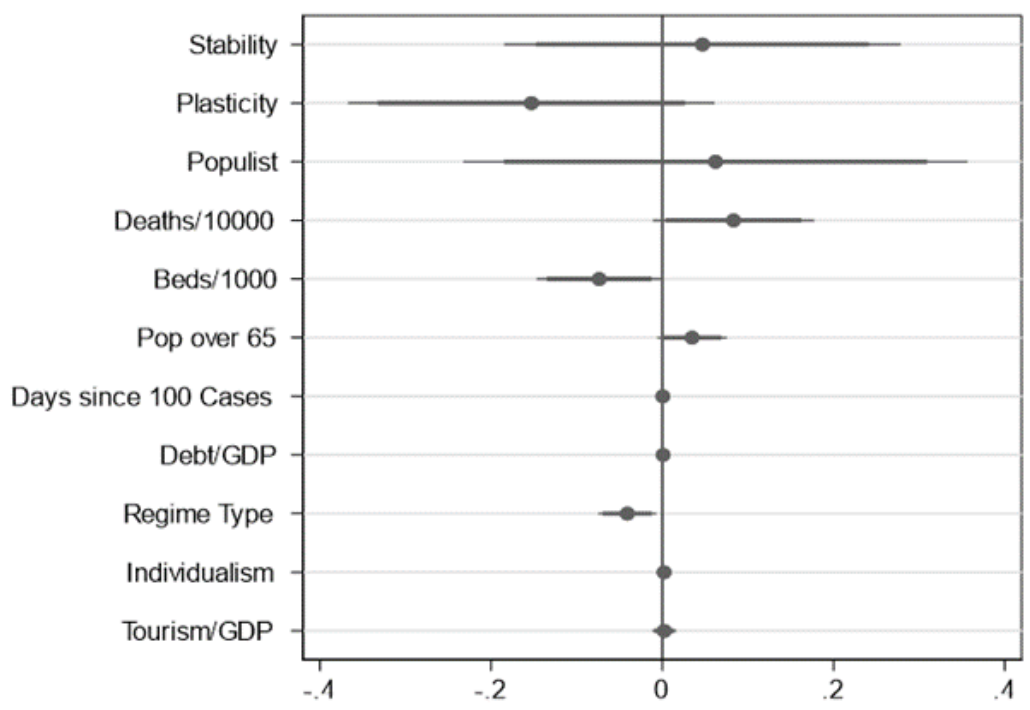

Markers indicate coefficients estimated from OLS regressions (panel a) and negative binomial regressions (panel b) using multiple imputed data; thick bars indicate confidence intervals at the 95-percent level; thin bars indicate confidence intervals at the 90-percent level. For full results, see Table B3 (panel a) and B4 (panel b) in Appendix B.

\section{Figure 2}

Determinants of International Travel Controls 
Figure 3. Determinants of Financial Relief

(a) Magnitude (average score)

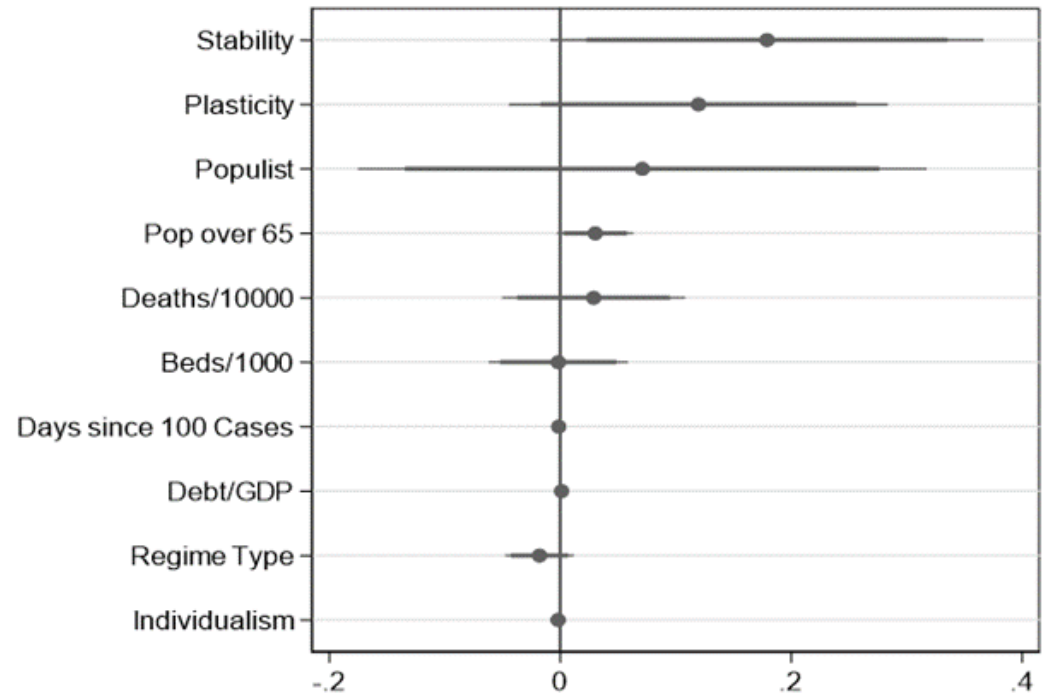

(b) Promptness (number of days at minimum value)

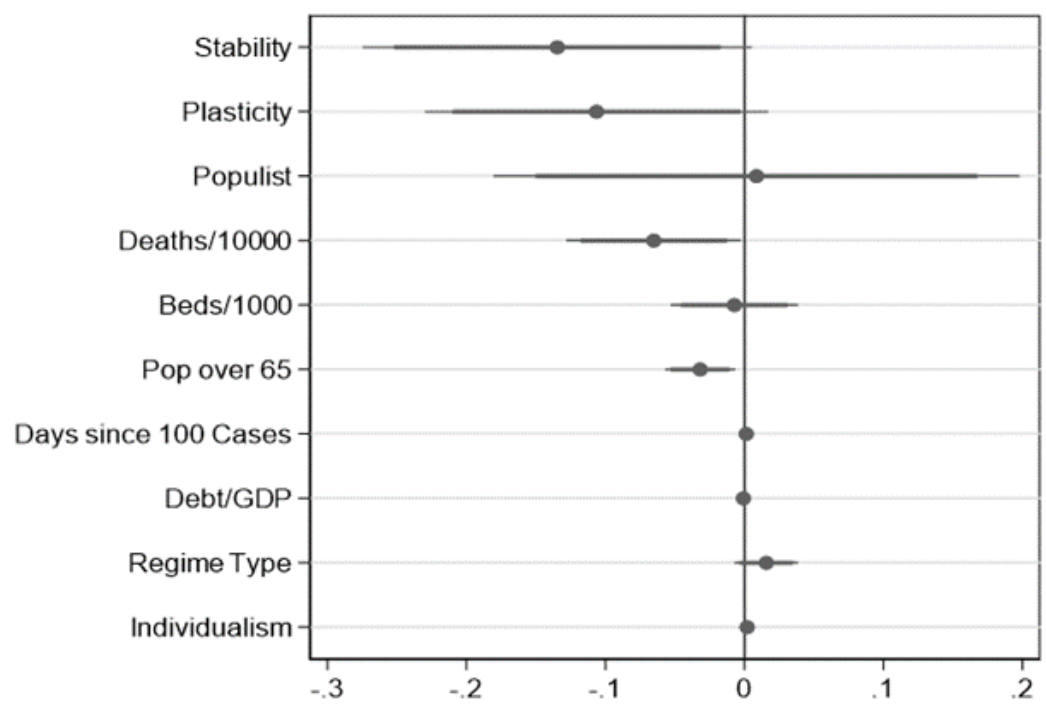

Markers indicate coefficients estimated from OLS regressions (panel a) and negative binomial regressions (panel b) using multiple imputed data; thick bars indicate confidence intervals at the 95-percent level; thin bars indicate confidence intervals at the 90-percent level. For full results, see Table B3 (panel a) and B4 (panel b) in Appendix B.

\section{Figure 3}

Determinant of Financial Relief 


\section{Figure 4. Determinants of Overall Government Response}

(a) Magnitude (average score)

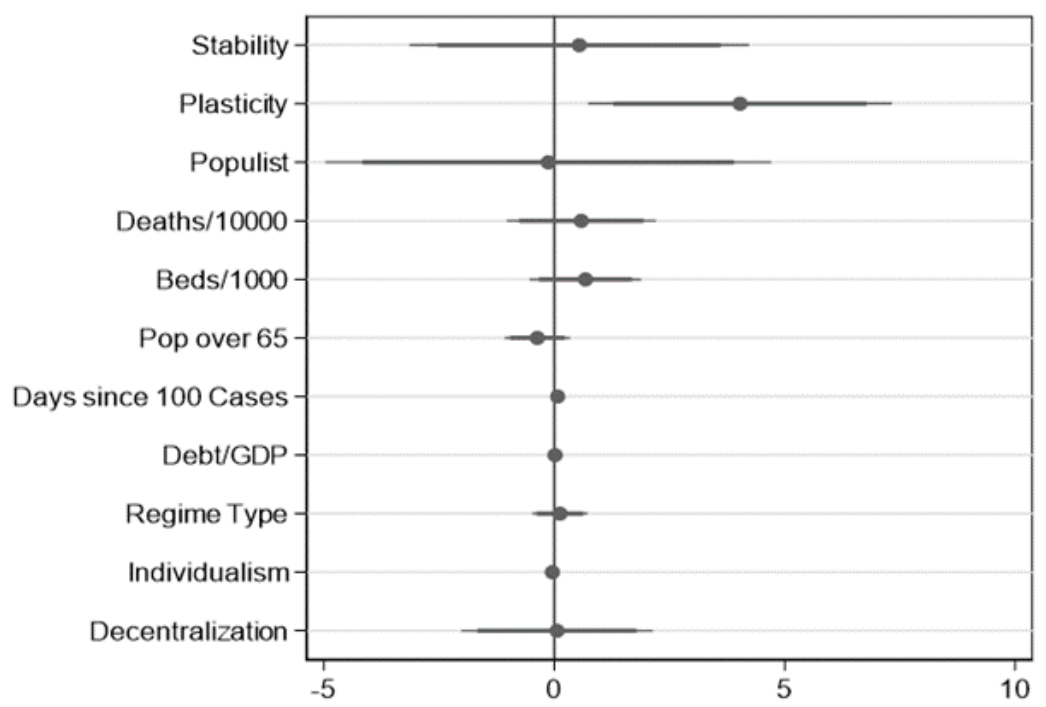

(b) Promptness (number of days at minimum value)

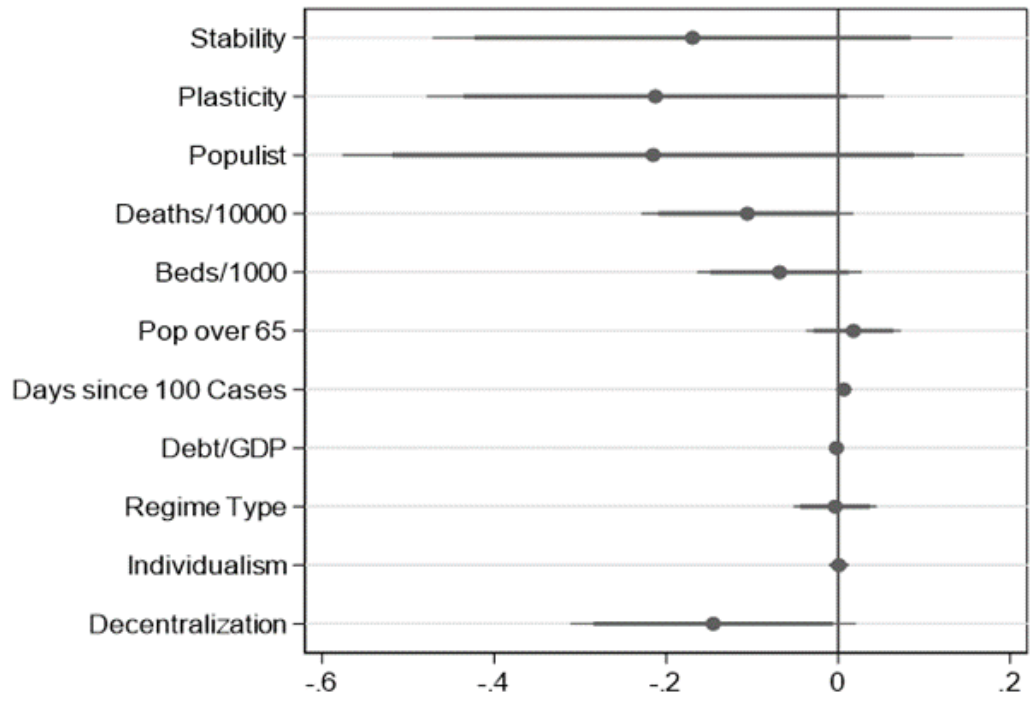

Markers indicate coefficients estimated from OLS regressions (panel a) and negative binomial regressions (panel b) using multiple imputed data; thick bars indicate confidence intervals at the 95-percent level; thin bars indicate confidence intervals at the 90-percent level. For full results, see Table B3 (panel a) and B4 (panel b) in Appendix B.

\section{Figure 4}

Determinant of Overall Government Relief 


\section{Figure 5. Moderation of Decentralization on the Impact of Plasticity on Government Response (Average)}

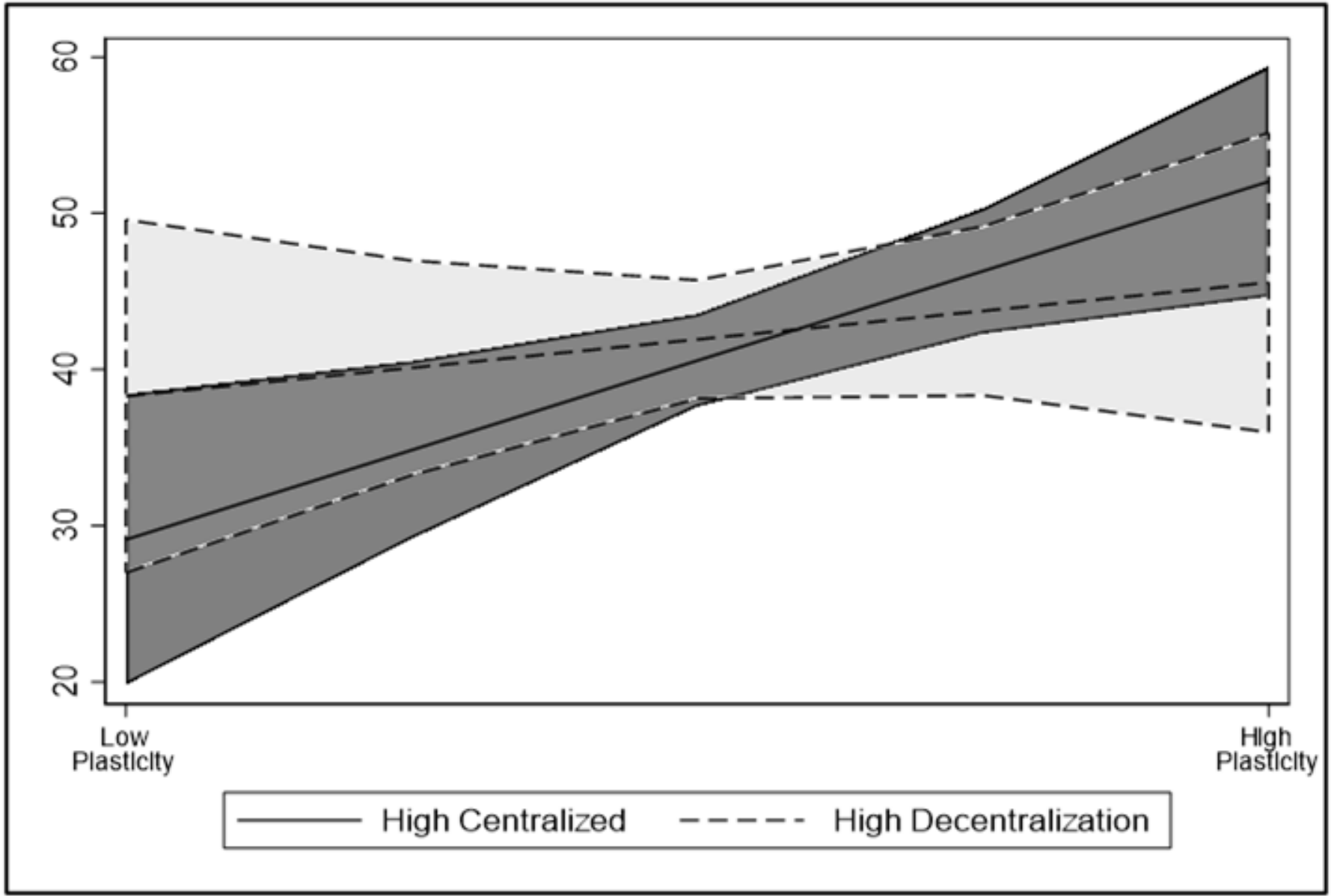

The mid-line represents predictive margins derived from the OLS regression in Figure 4. Bars represent confidence intervals at the $84 \%$ level (corresponding to $\mathrm{p}<0.05$, see MacGregor-Fors \& Payton, 2013).

Figure 5

Moderation of Decentralization on the Impact of Plasticity on Government Response (Average)

\section{Supplementary Files}

This is a list of supplementary files associated with this preprint. Click to download.

- Appendices.docx 